\title{
Uncomplicated Hypertension
}

National Cancer Institute

\section{Source}

National Cancer Institute. Uncomplicated Hypertension. NCI Thesaurus. Code C4785.

A condition of high blood pressure without resulting clinical disorders. 